\title{
Clinicopathological and Genetic Analyses of Small Cell Neuroendocrine Carcinoma of the Prostate: Histological Features for Accurate Diagnosis and Toward Future Novel Therapies Short Running Title: Characteristics of Prostatic Small Cell Neuroendocrine Carcinoma
}

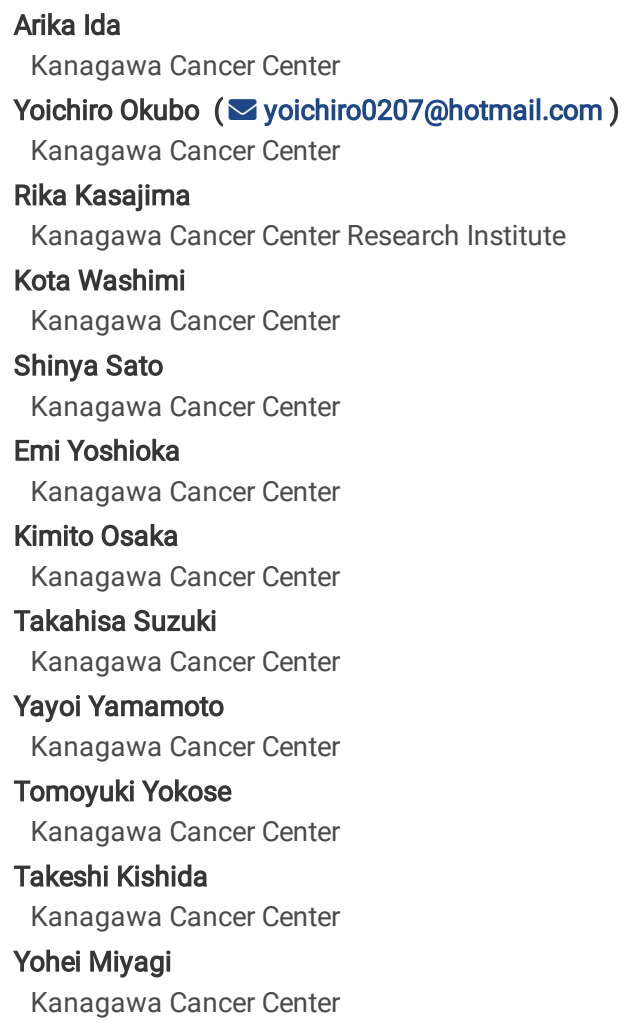

Research Article

Keywords: adenocarcinoma, small cell neuroendocrine carcinoma, ALK, PIK3CA, prostate

Posted Date: September 21st, 2021

DOl: https://doi.org/10.21203/rs.3.rs-913584/v1

License: (9) (1) This work is licensed under a Creative Commons Attribution 4.0 International License. Read Full License 


\section{Abstract}

Differentiating small cell neuroendocrine carcinoma (SCNC) of the prostate from prostatic cancer with diffuse neuroendocrine (NE) differentiation based on morphological features alone can be challenging. Given that treatment strategies vary depending on histological type, accurate diagnosis is critical. This study firstly aimed to identify the accurate diagnostic factors for primary prostate NE tumors. Furthermore, the possibility of novel treatment strategies through genetic analysis is also an aim. Specifically, prostate biopsies conducted in our hospital between January 2017 and May 2020 were included. As a result seven cases of SCNC and four cases of prostatic cancer with diffuse NE differentiation were identified. No significant differences in serum neuron-specific enolase (NSE), pro-gastrin-releasing peptide (ProGRP), and prostate-specific antigen (PSA) levels were observed between SCNC and adenocarcinoma with diffuse NE differentiation. The Ki-67 labeling index was significantly higher and PSA immunoreactivity tended to be lower in SCNC. Genetic analysis did not detect any ALK mutations but confirmed several other mutations, including those of PIK3CA and TP53. In conclusion, given the heterogeneity in serum NE markers in SCNC, diagnosis based on these markers alone is difficult. A high Ki-67 labeling index and low PSA immunoreactivity may be useful for diagnosing, but p53 immunoreactivity is insufficient to distinguish these tumors. Although further studies are required to interpret the results of the genetic analysis involving ALK, PIK3CA, and TP53 mutations, the results of our genetic analysis suggest that PIK3CA mutations in SCNC of the prostate may provide a novel therapeutic strategy.

\section{Introduction}

Adenocarcinoma constitutes the majority of histological types of prostate cancer (1). Primary neuroendocrine (NE) tumors of the prostate have also been identified and can be divided into four types based on the World Health Organization classification: adenocarcinoma with NE differentiation, welldifferentiated NE tumor, small cell NE carcinoma (SCNC), and large cell NE carcinoma (2). Of these, adenocarcinoma with NE differentiation and SCNC occur at a certain frequency (2). Approximately $0.5 \%$ to $2 \%$ of cases of primary SCNC of the prostate have been reported among prostate malignancies (3), in which morphological features are essential for the diagnosis of this tumor (4). However, diagnosis based on morphological features alone is sometimes challenging. Moreover, positive immunoreactivity for NE markers does not always provide a definitive diagnosis of NE carcinoma of the prostate due to the concept of prostate adenocarcinoma with NE differentiation (5). Given that therapeutic strategies differ depending on histological type, diagnoses are critical $(4,6)$.

An aggressive variant of SCNC occurs in castration-resistant prostate cancer (CRPC) after hormonal therapy and taxane chemotherapy (7-9), referred to as therapy-related NE prostate cancer (t-NEPC) (8). Genomic and transcriptional alterations are known to occur in CRPC cases, resulting in SCNC (10). De novo type SCNC may occur, and there are several reports on the frequency of de novo SCNC and t-NEPC cases. A high proportion of t-NEPC cases among patients with SCNC of the prostate has been reported (11), whereas other studies have indicated that SCNC cases constitute approximately equal proportions of tNEPC and de novo types (8). In this regard, various mechanisms, including the presence or absence of a history of therapy, may be associated with SCNC of the prostate (12).

Recently, the concept of prostate cancer with diffuse NE differentiation has been reported, raising concerns regarding its differentiation from SCNC (5). Here, we first aimed to clarify the characteristics of prostate NE tumors diagnosed by biopsy and determine factors contributing to an accurate diagnosis. Moreover, the presence of $A L K$ mutation (ALK F1174C) in SCNC of the prostate was reported, highlighting its potential use as a novel therapeutic target (13). Therefore, we further explored the possibility of future novel therapeutic strategies.

\section{Materials And Methods}

\section{Study design}

This study included cases biopsied after January 2017 due to the shift from systemic prostate needle biopsies to the addition of extra biopsies based on prebiopsy magnetic resonance imaging findings at our institute. As per the previous methodology of our institution, Primary pathological findings were first recorded by YO and reviewed by a second pathologist (YM) according to the 2014 International Society of Urological Pathology system (14-16).

In the event of disagreement on diagnostic findings, another trained pathologist was recruited for discussion until a final consensus was reached. From January 2017, clinical information, including age, body mass index, and pre-biopsy serum prostate-specific antigen (PSA) levels, and pathological findings, such as the presence of tumor lesions, histological type (including suspected NE tumors), number of positive scores, highest Gleason grade (only for adenocarcinoma cases), lesion length, and immunohistochemical confirmation of NE marker expression, were recorded by YO for database generation. Cases were extracted from the database if NE tumors were suspected based on morphological findings and immunohistochemical confirmation of NE markers, such as synaptophysin and chromogranin A. Subsequently, cases were re-reviewed using actual specimens. Serum neuron-specific enolase (NSE) and pro-gastrinreleasing peptide (ProGRP) levels were confirmed in the most recent values at the time of biopsy. Metastasis to other organs and prognosis were confirmed using electronic medical records. The diagnostic criteria for small cell neuroendocrine carcinoma (SCNC) of the prostate were based on the World Health Organization classification (2), with emphasis on morphology and immunoreactivity of NE markers. Given that prostate cancer can exhibit partial NE differentiation, adenocarcinoma with NE in this study was defined as cases with diffuse immunoreactivity for NE markers (prostatic carcinoma with diffuse NE differentiation), based on a previous report (5). The definition of "diffuse" is controversial, but in this study, we included cases in which at least $50 \%$ were positive. In each of the cases in this study, only a prostate biopsy was conducted, and no additional surgically resected specimens were obtained.

\section{Immunohistochemical analyses}

Immunohistochemical examinations were performed on available paraffin blocks using primary antibodies against the following markers: androgen receptor (AR; Nichirei, clone AR441; 1:1 dilution), chromogranin A (clone 1E2; 1:5 dilution), Ki-67 (Dako, clone MIB-1; 1:50 dilution), prostein (Dako, clone 10E3; 1:100 dilution), PSA (Dako, clone ER-PR8; 1:50 dilution), p53 (Nichirei, clone D0-7; 1:1 dilution), and synaptophysin (Roche, clone 4B5; 1:1 dilution). CD56 was not 
assessed in this study due to its low specificity (17). The $\mathrm{H}$-score was used for immunohistochemical evaluation and was calculated by multiplying the staining intensity ( 0 , negative; 1 , weakly positive; 2 , moderately positive; and 3 , strongly positive) by the percentage of cells exhibiting that staining intensity $(0-100)$, resulting in a score in the range of $0-300$ (18). For the Ki-67 labeling index, hotspots were assessed (19-21). Areas containing a high number of Ki67-positive cells (at least 500 cells) were selected, and the percentage of positive cells was calculated. For cases of mixed SCNC-adenocarcinoma, immunostaining for adenocarcinoma and small cell carcinoma areas was performed.

\section{Examination of hotspot driver mutations using a gene panel}

To explore the possibility of novel therapeutic strategies, we examined hotspot driver mutations using the lon AmpliSeq ${ }^{\mathrm{TM}}$ Cancer Hotspot Panel v2 (CHPv2, Thermo Fisher Scientific, Inc.). Next-generation sequencing (NGS) was performed as described previously (22-24). Tumor tissues were obtained from thin sections ( $4 \mu \mathrm{m}$ thickness per slice) prepared from formalin-fixed and paraffin-embedded (FFPE) tissue blocks by manually dissecting the tumor area. DNA was extracted from FFPE tissues using the GeneRead FFPE Kit (QIAGEN, Hilden, Germany) according to the manufacturer's instructions and was quantified using Qubit 2 (Thermo Fisher Scientific, Inc., Waltham, MA). DNA (10 ng) was applied to library construction with the CHPv2 based on lon Torrent AmpliSeq ${ }^{\mathrm{TM}}$ technology (Thermo Fisher Scientific, Inc.) and subjected to sequencing with the lon PGM next-generation sequencer (Thermo Fisher Scientific, Inc.). The CHPv2 for NGS is a gene panel for analyzing well-characterized mutation hotspots of the following 50 cancer-related genes: $A B L 1, A K T 1, A L K, A P C, A T M$, BRAF, CDH1, CDKN2A, CSF1R, CTNNB1, EGFR, ERBB2, ERBB4, EZH2, FBXW7, FGFR1, FGFR2, FGFR3, FLT3, GNA11, GNAQ, GNAS, HNF1A, HRAS, IDH1, IDH2, JAK2, JAK3, KDR, KIT, KRAS, MET, MLH1, MPL, NOTCH1, NPM1, NRAS, PDGFRA, PIK3CA, PTEN, PTPN11, RB1, RET, SMAD4, SMARCB1, SMO, SRC, STK11, TP53, and VHL. The sequenced data were processed and analyzed using Torrent Suite 5.12.2 and lon Reporter version 5.16 (Thermo Fisher Scientific Inc.). Quality control reports were acquired from Torrent Suite. To identify somatic variants, single nucleotide variations and insertion or deletion mutations with a coverage of 20 base pairs and encoding amino acid sequence substitutions comparable to the UCSC hg19 reference genome sequence were first selected. Next, single-nucleotide polymorphisms (SNPs) were excluded using these sequences as queries against CoS-MIC (http://cancer.sanger.ac.uk/cosmic), dbSNPs (NCBI, NIH; https://www.ncbi.nlm.nih.gov/projects/SNP/), and other publicly accessible databases. Finally, mutations with $>5 \%$ allele frequency were defined as somatic nonsynonymous mutations and further evaluated. The biological significance of the identified somatic mutations was assessed using COSMIC, ClinVar (NCBI; https://www.ncbi.nlm.nih.gov/clinvar/).

\section{Statistical analyses}

Statistical analyses were performed using International Business Machines (IBM) Statistical Package for the Social Sciences Statistics version 25 (IBM Corp., Armonk, NY, USA). Serum NSE, ProGRP, and PSA levels and the H-score and Ki-67 labeling index were subjected to statistical analysis. Student's t-test was used to compare two groups. One-way analysis of variance (one-way ANOVA) and the Bonferroni post hoc test were used to compare three groups. A p-value $<0.05$ was considered statistically significant.

\section{Results}

\section{Clinicopathological results}

Between January 2017 and May 2021, 1014 prostate biopsies were conducted at our hospital, among which 654 (64.5\%) prostate cancer cases were confirmed. After primary evaluation of hematoxylin and eosin-stained specimens, immunohistochemistry of synaptophysin and chromogranin A was conducted in 32 cases $(32 / 654,4.9 \%)$ because there were cases suspected of neuroendocrine tumors but could not be determined by morphological images alone. Components positive for both synaptophysin and chromogranin A were identified in 11 cases. Seven cases (7/654, 1.1\%) contained SCNC components, two of which were pure SCNC and five were mixed SCNC-adenocarcinoma. Four of the 11 cases (4/654, 0.6\%) were prostatic carcinoma with diffuse NE differentiation (Figure 1). Although t-NEPC accounts for a subset of SCNC of the prostate $(10,11)$, cases in this study were treatment-naive, with the exception of a patient in one case who had been treated with hormonal therapy (Case 6) for 18 months before the biopsy.

All prostatic carcinomas with diffuse NE differentiation were Gleason Grade 5 and were difficult to differentiate from SCNC morphologically. In contrast to SCNC, these cases exhibited the following features: nuclear structures with densely stained nuclei and inconspicuous nucleoli observed at high magnification, lower nuclear-to-cytoplasmic ratio, and foamy cytoplasm, consistent with previous reports $(2,5)$. Age, histological type, serum NSE, and ProGRP and PSA levels; organs with metastasis; and outcomes are summarized in Table 1. The mean ( \pm standard deviation) serum NSE, ProGRP, and PSA values in SCNC were $51.9 \pm 78.7 \mathrm{ng} / \mathrm{mL}, 2381.3 \pm 5086.2 \mathrm{pg} / \mathrm{mL}$, and $31.3 \pm 56.7 \mathrm{ng} / \mathrm{mL}$, respectively, whereas these values in prostate cancer with diffuse NE differentiation were $10.8 \pm 5.1 \mathrm{ng} / \mathrm{mL}, 50.5 \pm 35.3 \mathrm{pg} / \mathrm{mL}$, and $1603.7 \pm 2396.5 \mathrm{ng} / \mathrm{mL}$, respectively (PSA values in the case with hormonal therapy and unmeasured values were excluded). There were no significant differences in serum NSE, Pro GRP, and PSA levels between SCNC and prostate cancer with diffuse NE differentiation (Student's t-test, $p=0.257, p=0.313$, and $p=0.281$, respectively).

\section{Immunohistochemical results}

One case with a history of hormonal therapy before the biopsy was excluded. Immunohistochemical results of the remaining 10 cases are summarized in Tables 2 and 3 and Figures 2 and 3. Compared with adenocarcinoma components, SCNC exhibited a significantly higher Ki-67 labeling index in mixed SCNCadenocarcinoma (one-way ANOVA, p<0.01) and prostatic carcinoma with diffuse NE differentiation (one-way ANOVA, p<0.01). Immunohistochemical PSA positivity in SCNC demonstrated a trend of lower H-scores, although this did not reach statistical significance $(p=0.09$ and $p=0.1$ for adenocarcinoma components in mixed SCNC-adenocarcinoma and prostatic carcinoma with diffuse NE differentiation, respectively). Cases with extremely high positivity (overexpression) or complete negativity (null-type) for p53 were identified in both SCNC and prostatic carcinoma with diffuse NE differentiation (Figures 4 and 5). No significant differences were noted in any immunohistochemical finding pertaining to adenocarcinoma components between mixed SCNCadenocarcinoma and prostatic carcinoma with diffuse NE differentiation. 
Hotspot driver mutations were evaluated in available cases, including one of the two pure SCNCs, three of the four prostatic carcinomas with diffuse NE differentiation, and four of the five mixed SCNC-adenocarcinoma cases. Both SCNC and adenocarcinoma components were examined in mixed SCNCadenocarcinoma case. The one pure SCNC was subjected to the FoundationOne CDx assay (Foundation Medicine Inc., Cambridge, MA). In summary, ALK mutation was not detected, whereas TP53 mutation was the most frequently identified. In one case of SCNC, a mutation in PIK3CA was also detected. Results are summarized in Table 4.

\section{Discussion}

SCNC of the prostate is a rare but highly aggressive cancer (8). In this study, seven cases of SCNC (including two pure cases and five mixed SCNCadenocarcinoma cases) were identified with a frequency of approximately $1 \%$. Further, four cases of prostatic carcinoma with diffuse NE differentiation were observed. Generally, prostatic carcinoma with diffuse NE differentiation does not differ from the conventional type of prostate adenocarcinoma with similarly high GG in prognosis (17), although this remains controversial (2). Further, the difference in prognosis between SCNC and prostatic carcinoma with diffuse NE differentiation remains controversial $(2,4,6)$. In this study, two of the four patients with prostatic carcinoma with diffuse NE differentiation died (although one death was due to a complicated gastric cancer), and three of the seven patients with SCNC died. However, cases of prostate cancer with diffuse NE differentiation in this study were limited to those with suspected SCNC morphologically and confirmed immunoreactivity for NE markers, all of which were aggressive cases corresponding to GG5. Thus, assessing the true difference in prognosis between SCNC and prostatic carcinoma with diffuse NE differentiation remains challenging. Lymph nodes and bones are well-established metastatic sites in prostate cancer (14, 25-27). Apart from these organs, one case of liver metastasis was identified among the four cases of adenocarcinoma (Case 1), whereas distant metastases were identified in three of the seven cases of SCNC (Cases 5-7, brain, liver, lung, and skin). Although the number of cases should be considered, SCNC exhibited a tendency of distant metastases to sites other than lymph nodes or bones, consistent with previous reports $(8,28,29)$. Clinical data revealed a trend of low serum PSA levels and extremely high serum ProGRP levels in SCNC cases. However, one case of SCNC with high PSA levels was identified, and four of the seven SCNC cases did not exhibit high ProGRP and NSE levels. Furthermore, the mean serum NSE, ProGRP, and PSA values were different between SCNC and prostatic carcinoma with diffuse NE differentiation, although the differences were not statistically significant. Although the small number of cases should be considered, the heterogeneity of serum NSE and ProGRP levels in SCNC cases may also be relevant. Although extremely high serum NSE and ProGRP values suggest the presence of SCNC, it may be difficult to completely distinguish between SCNC and diffusely NE-differentiated prostate cancer based on serum PSA and NE marker values alone.

ALK mutation was not detected in this study. Including the FoundationOne CDx assay results of one case, only five SCNC cases were genetically analyzable (Cases 4-7 and Case 11); therefore, further investigations are warranted to elucidate the profile of targetable mutations, such as ALKF1174C in SCNC of the prostate. Comparison of gene mutations between the SCNC and adenocarcinoma components from the same mixed SCNC-adenocarcinoma was possible for two cases. No mutations were identified in the adenocarcinoma component, and ERBB2 mutation in the SCNC component was noted in one case.

The other case revealed truncating loss-of-function mutations in the tumor suppressor genes PTEN and TP53 in the adenocarcinoma component. Notably, the SCNC component of this case shared the same TP53 mutation at the nucleotide alteration level (c.820_821delGT; p.Val274fs), implying the existence of a common precursor lesion committed to tumorigenesis $(30,31)$. The SCNC component did not contain PTEN mutations. PTEN mutations appeared at or after the splitting of the two histologic types. Two cases of TP53 truncating mutations exhibited a null-type pattern on immunostaining for p53. Consistent with reports on other cancers (32), nonsynonymous amino acid-replacing TP53 mutations were identified in two cases of prostate cancer with diffuse NE differentiation and one case of pure SCNC with high expression of p53. Moreover, a PIK3CA mutation (p. His1047Arg) was detected in one case of SCNC (Case 7). PIK3CA mutations have been identified in various types of cancers (33) and have also been reported to be a genetic driver of prostate cancer (34). However, to the best of our knowledge, this mutation has not been reported in prostate SCNC. A combination of PIK3CA inhibitors, alpelisib and fulvestrant, has been proposed as a novel therapy for breast cancer (35-37). Our genetic findings suggest that the presence of this PIK3CA mutation in SCNC may offer a novel therapeutic target.

Histopathologically, the basic morphological features of SCNC are relatively small tumor cells with inconspicuous nucleoli, densely stained nuclei with increased chromatin, a high nuclear-to-cytoplasmic ratio, and stretchability often resulting in nuclear lines (38). The significance of these morphological features has increased due to the establishment of the concept of prostatic carcinoma with diffuse NE differentiation (2). However, distinguishing SCNC from prostatic carcinoma with diffuse NE differentiation based on morphology and immunohistochemistry for NE markers alone can be challenging. The H-score for chromogranin A tended to be higher for SCNC than for prostatic carcinoma with diffuse NE differentiation, although this difference was not statistically significant. Further, no significant difference in immunoreactivity for synaptophysin was noted between the two tumor types, highlighting the difficulty in differentiating SCNC from prostatic carcinoma with diffuse NE differentiation based solely on immunoreactivity to NE markers. Although high p53 immunoreactivity has been reported in SCNC of other organs (39-41), both SCNC and adenocarcinoma with diffuse NE differentiation of the prostate frequently exhibited a mutated TP53 pattern, that is, overexpression or null-type, which precluded these tumor types from being distinguished. In particular, both prostate cancer with diffuse NE differentiation and SCNC may exhibit overexpression or null-type immunoreactivity for p53. Pathologists, urologists, and oncologists should therefore be aware that p53 immunoreactivity is insufficient to distinguish between these two histological types. In contrast, the Ki-67 labeling index, a well-known indicator of malignant potential (42-45), was significantly different between the two histologic types. The average labeling index for SCNC was $70 \%$, which was approximately three times significantly higher than that for prostatic carcinoma with diffuse NE differentiation. With regard to prostatic epithelial cell markers, a degree of AR and prostein immunoreactivity was observed in SCNC, whereas less PSA immunoreactivity was noted, although this did not reach statistical significance. In SCNC of the prostate, AR and prostein are not useful in differentiating prostate cancer, as they maintain immunoreactivity. However, PSA, in addition to the Ki-67 labeling index, might be an auxiliary marker in the diagnosis of SCNC, because a considerable, although not statistically significant, reduction in PSA immunoreactivity was observed in SCNC. 
Further studies are warranted, our findings suggest that a high $\mathrm{Ki}-67$ labeling index and low PSA immunoreactivity may contribute to an accurate diagnosis of SCNC. Although other novel markers for SCNCs have been reported $(46,47)$, an advantage of our approach is that it can be applied using antibodies commonly employed in the diagnostic pathology department. In addition, immunohistochemistry for prostate markers other than PSA, such as AR and prostein (48-50), may be suitable for excluding metastatic SCNC from other organs. Nevertheless, we once more wish to state the limitations of this study. The study includes seven cases of SCNC and 4 cases of prostatic carcinoma with diffuse NE differentiation. Therefore, we acknowledge that the small number of cases is one of the limitations of this study.

\section{Conclusion}

Our study provides insight into histological characteristics that may facilitate the diagnosis of SCNC of the prostate. Moreover, genetic analysis findings suggest that the presence of PIK3CA mutation in this tumor may offer a novel therapeutic target.

\section{Abbreviations}

ANOVA, analysis of variance; AR, androgen receptor; CRPC, castration-resistant prostate cancer; FFPE, formalin-fixed and paraffin-embedded; NE, neuroendocrine; NGS, next-generation sequencing; NSE, neuron-specific enolase; ProGRP, pro-gastrin-releasing peptide; PSA, prostate-specific antigen; SCNC, small cell neuroendocrine carcinoma; SNPs, single-nucleotide polymorphism; t-NEPC, therapy-related NE prostate cancer

\section{Declarations}

\section{Funding}

This work was supported by JSPS KAKENHI (funding granted to YO, grant number: 17K08713, RK, grant number: 16K19099 and 20K09068, KW, grant number: 20K16210, SS, grant number: 20K09422, YM, grant number: 20K09093) from the Ministry of Education, Culture, Sports, Science, and Technology of Japan and by Kanagawa Cancer Center and Research Institute/Kanagawa Prefectural Hospital Organization (funding granted to Y0, grant number: 2021-1).

\section{Conflicts of interest/Competing interests}

All authors declare that there is no conflict of interest regarding the publication of this paper.

\section{Data availability}

The dataset supporting the conclusions of this article is included within the article and all material is available upon request.

\section{Authors' contributions}

Arika Ida: Gathering of the required information from the database, Reassessment of the specimens with Yoichiro Okubo, Genetic analysis with Rika Kasajima, Producing a draft of the manuscript. Yoichiro Okubo: Review of the specimens, Construction of the database, Integration of the data, Final revisions of the manuscript. Rika Kasajima: Genetic analysis, Interpretation of the results with Arika Ida, Yoichiro Okubo, and Yohei Miyagi. Kota Washimi, Shinya Sato, and Emi Yoshioka: Participation in some of the reviews of cases with unclear diagnoses and provision of advice on the results of genetic analysis. Kimito Osaka and Takahisa Suzuki: Review, organization, and provision of the clinical data to Arika Ida and Yoichiro Okubo, Confirmation of the patients' prognoses by contacting other facilities as necessary. Yayoi Yamamoto: Provision of advices on tumor spread, especially distant metastasis. Tomoyuki Yokose: Revision of some parts of the manuscript pertaining to pathological diagnosis from the perspective of a senior pathologist and provision of advice on the results of genetic analysis. Takeshi Kishida: Provision of detailed clinical information to Yoichiro Okubo, Revision of some parts of the manuscript. Yohei Miyagi: Review and reassessment of the specimens and revision of the manuscript as the senior pathologist. All authors have read and approved the final version of the manuscript.

\section{Acknowledgements}

We would like to thank Sachie Osanai and Mitsuyo Yoshihara for their excellent technical support. We also wish to thank Editage (www.editage.jp) for English language editing.

\section{Ethics approval and consent participate}

Informed consent was obtained from the patients for research and publication. This study was conducted in accordance with the Declaration of Helsinki and approved by the Ethics Review Committee of the Kanagawa Cancer Center (approval number: 2019-36, June 26, 2019).

\section{References}

1. van Leenders G, van der Kwast TH, Grignon DJ, Evans AJ, Kristiansen G, Kweldam CF, et al. The 2019 International Society of Urological Pathology (ISUP) Consensus Conference on Grading of Prostatic Carcinoma. Am J Surg Pathol. 2020; 44(8):e87-e99. doi: 10.1097/PAS.0000000000001497.

2. Epstein JIAMB, Evans AJ, Huang J, Rubin MA. WHO classification of tumours of the urinary system and male genital organs. 4th ed. ed. Lyon: World Health Organization; 2016.

3. Bell PD, Huber AR, Agostini-Vulaj D. Clinicopathologic features of metastatic small cell carcinoma of the prostate to the liver: a series of four cases. Diagn Pathol. 2021;16(1):35. doi:10.1186/s13000-021-01096-1. 
4. Hu J, Han B, Huang J. Morphologic Spectrum of Neuroendocrine Tumors of the Prostate: An Updated Review. Arch Pathol Lab Med. 2020;144(3):320-5. doi:10.5858/arpa.2019-0434-RA.

5. Fine SW. Neuroendocrine tumors of the prostate. Mod Pathol. 2018;31(S1):122-32. doi:10.1038/modpathol.2017.164.

6. Kardoust Parizi M, Iwata T, Kimura S, Janisch F, Abufaraj M, Karakiewicz PI, et al. Focal Neuroendocrine Differentiation of Conventional Prostate Adenocarcinoma as a Prognostic Factor after Radical Prostatectomy: A Systematic Review and Meta-Analysis. Int J Mol Sci 2019; 20(6). doi:10.3390/ijms20061374.

7. Terry S, Beltran H. The many faces of neuroendocrine differentiation in prostate cancer progression. Front Oncol. $2014 ; 4: 60$. doi:10.3389/fonc. 2014.00060 .

8. Conteduca V, Oromendia C, Eng KW, Bareja R, Sigouros M, Molina A, et al. Clinical features of neuroendocrine prostate cancer. Eur J Cancer. 2019;121:718. doi:10.1016/j.ejca.2019.08.011.

9. Wang Z, Shen H, Ma N, Li Q, Mao Y, Wang C, et al. The Prognostic Value of Androgen Receptor Splice Variant 7 in Castration-Resistant Prostate Cancer Treated With Novel Hormonal Therapy or Chemotherapy: A Systematic Review and Meta-analysis. Front Oncol. 2020;10:572590. doi:10.3389/fonc.2020.572590.

10. Ma X, Huang J. Predicting clinical outcome of therapy-resistant prostate cancer. Proc Natl Acad Sci U S A. 2019;116(23):11090-2. doi:10.1073/pnas.1906812116.

11. Bhagirath D, Liston M, Akoto T, Lui B, Bensing BA, Sharma A, et al. Novel, non-invasive markers for detecting therapy induced neuroendocrine differentiation in castration-resistant prostate cancer patients. Sci Rep. 2021;11(1):8279. doi:10.1038/s41598-021-87441-2.

12. Akamatsu S, Inoue T, Ogawa O, Gleave ME. Clinical and molecular features of treatment-related neuroendocrine prostate cancer. Int J Urol. 2018;25(4):345-51. doi:10.1111/iju.13526.

13. Carneiro BA, Pamarthy S, Shah AN, Sagar V, Unno K, Han H, et al. Anaplastic Lymphoma Kinase Mutation (ALK F1174C) in Small Cell Carcinoma of the Prostate and Molecular Response to Alectinib. Clin Cancer Res. 2018;24(12):2732-9. doi:10.1158/1078-0432.CCR-18-0332.

14. Okubo Y, Sato S, Osaka K, Yamamoto Y, Suzuki T, Ida A, et al. Clinicopathological Analysis of the ISUP Grade Group And Other Parameters in Prostate Cancer: Elucidation of Mutual Impact of the Various Parameters. Front Oncol. 2021;11:695251. doi:10.3389/fonc.2021.695251.

15. Epstein JI, Egevad L, Amin MB, Delahunt B, Srigley JR, Humphrey PA, et al. The 2014 International Society of Urological Pathology (ISUP) Consensus Conference on Gleason Grading of Prostatic Carcinoma: Definition of Grading Patterns and Proposal for a New Grading System. Am J Surg Pathol. 2016; 40(2):244 - 52. doi: 10.1097/PAS.0000000000000530.

16. Kweldam CF, van Leenders GJ, van der Kwast T. Grading of prostate cancer: a work in progress. Histopathology. 2019;74(1):146-60. doi:10.1111/his. 13767 .

17. Parimi V, Goyal R, Poropatich K, Yang XJ. Neuroendocrine differentiation of prostate cancer: a review. Am J Clin Exp Urol. 2014;2(4):273-85. doi.

18. Mannan R, Bhasin TS, Manjari M, Singh G, Bhatia PK, Sharma S. Immunohistochemical expression of Ets-related gene-transcriptional factor in adenocarcinoma prostate and its correlation with Gleason score. Indian J Pathol Microbiol. 2016;59(4):489-95. doi:10.4103/0377-4929.191794.

19. Niazi MKK, Tavolara TE, Arole V, Hartman DJ, Pantanowitz L, Gurcan MN. Identifying tumor in pancreatic neuroendocrine neoplasms from Ki67 images using transfer learning. PLoS One. 2018;13(4):e0195621. doi:10.1371/journal.pone.0195621.

20. Okubo Y, Sakai M, Yamazaki H, Sugawara Y, Samejima J, Yoshioka E, et al. Histopathological study of carcinoma showing thymus-like differentiation (CASTLE). Malays J Pathol. 2020;42(2):259-65. doi.

21. Govind D, Jen KY, Matsukuma K, Gao G, Olson KA, Gui D, et al. Improving the accuracy of gastrointestinal neuroendocrine tumor grading with deep learning. Sci Rep. 2020;10(1):11064. doi:10.1038/s41598-020-67880-z.

22. Ono K, Kasajima R, Katayama K, Miyagi Y, Yokose T. Clinicopathological and molecular characteristics of endometrial neuroendocrine carcinomas reveal preexisting endometrial carcinoma origin. Pathol Int. 2021. doi:10.1111/pin.13108.

23. Manabe S, Kasajima R, Murakami S, Miyagi Y, Yokose T, Kondo T, et al. Analysis of targeted somatic mutations in pleomorphic carcinoma of the lung using next-generation sequencing technique. Thorac Cancer. 2020;11(8):2262-9. doi:10.1111/1759-7714.13536.

24. Ariura M, Kasajima R, Miyagi Y, Ishidera Y, Sugo Y, Oi Y, et al. Combined large cell neuroendocrine carcinoma and endometrioid carcinoma of the endometrium: a shared gene mutation signature between the two histological components. Int Cancer Conf J. 2017;6(1):11-5. doi:10.1007/s13691-0160263-9.

25. Klusa D, Lohaus F, Furesi G, Rauner M, Benesova M, Krause M, et al. Metastatic Spread in Prostate Cancer Patients Influencing Radiotherapy Response. Front Oncol. 2020;10:627379. doi:10.3389/fonc.2020.627379.

26. Selnaes KM, Kruger-Stokke B, Elschot M, Johansen H, Steen PA, Langorgen S, et al. Detection of Recurrent Prostate Cancer With (18)F-Fluciclovine PET/MRI. Front Oncol. 2020;10:582092. doi:10.3389/fonc.2020.582092.

27. Jin S, Wei J, Wang J, Wang B, Wu J, Gan H, et al. Prognostic Value of Local Treatment in Prostate Cancer Patients With Different Metastatic Sites: A Population Based Retrospective Study. Front Oncol. 2020;10:527952. doi:10.3389/fonc.2020.527952.

28. Zhang Q, Han Y, Zhang Y, Liu D, Ming J, Huang B, et al. Treatment-Emergent Neuroendocrine Prostate Cancer: A Clinicopathological and Immunohistochemical Analysis of 94 Cases. Front Oncol. 2020;10:571308. doi:10.3389/fonc.2020.571308.

29. Kobayashi K, Muto M, Shigematsu Y. Effective treatment of relapsed prostate small cell carcinoma with amrubicin: report of a case. Int Cancer Conf J. 2020;9(3):155-8. doi:10.1007/s13691-020-00416-4.

30. Nykamp K, Anderson M, Powers M, Garcia J, Herrera B, Ho YY, et al. Sherloc: a comprehensive refinement of the ACMG-AMP variant classification criteria. Genet Med. 2017;19(10):1105-17. doi:10.1038/gim.2017.37. 
31. Ruijs MW, Verhoef S, Rookus MA, Pruntel R, van der Hout AH, Hogervorst FB, et al. TP53 germline mutation testing in 180 families suspected of LiFraumeni syndrome: mutation detection rate and relative frequency of cancers in different familial phenotypes. J Med Genet. 2010;47(6):421-8. doi:10.1136/jmg.2009.073429.

32. Hussain I, Howard RS, Syed V, Allgauer M, Gong H, Xing D, et al. A Cell Line-based Immunohistochemical p53 Expression Pattern Control Panel. Int J Gynecol Pathol. 2019;38(5):449-58. doi:10.1097/PGP.0000000000000537.

33. Li WM, Hu TT, Zhou LL, Feng YM, Wang YY, Fang J. Highly sensitive detection of the PIK3CA (H1047R) mutation in colorectal cancer using a novel PCRRFLP method. BMC Cancer. 2016;16:454. doi:10.1186/s12885-016-2493-9.

34. Pearson HB, Li J, Meniel VS, Fennell CM, Waring P, Montgomery KG, et al. Identification of Pik3ca Mutation as a Genetic Driver of Prostate Cancer That Cooperates with Pten Loss to Accelerate Progression and Castration-Resistant Growth. Cancer Discov. 2018;8(6):764-79. doi:10.1158/2159-8290.CD-170867.

35. Rugo HS, Lerebours F, Ciruelos E, Drullinsky P, Ruiz-Borrego M, Neven P, et al. Alpelisib plus fulvestrant in PIK3CA-mutated, hormone receptor-positive advanced breast cancer after a CDK4/6 inhibitor (BYLieve): one cohort of a phase 2, multicentre, open-label, non-comparative study. Lancet Oncol. 2021;22(4):489-98. doi:10.1016/S1470-2045(21)00034-6.

36. Andre F, Ciruelos EM, Juric D, Loibl S, Campone M, Mayer IA, et al. Alpelisib plus fulvestrant for PIK3CA-mutated, hormone receptor-positive, human epidermal growth factor receptor-2-negative advanced breast cancer: final overall survival results from SOLAR-1. Ann Oncol. 2021;32(2):208-17. doi:10.1016/j.annonc.2020.11.011.

37. Ciruelos EM, Rugo HS, Mayer IA, Levy C, Forget F, Delgado Mingorance JI, et al. Patient-Reported Outcomes in Patients With PIK3CA-Mutated Hormone Receptor-Positive, Human Epidermal Growth Factor Receptor 2-Negative Advanced Breast Cancer From SOLAR-1. J Clin Oncol. 2021;39(18):2005-15. doi:10.1200/JCO.20.01139.

38. Montironi R, Cimadamore A, Lopez-Beltran A, Scarpelli M, Aurilio G, Santoni M, et al. Morphologic, Molecular and Clinical Features of Aggressive Variant Prostate Cancer. Cells. 2020; 9(5). doi:10.3390/cells9051073.

39. Quinn DI, Henshall SM, Head DR, Golovsky D, Wilson JD, Brenner PC, et al. Prognostic significance of p53 nuclear accumulation in localized prostate cancer treated with radical prostatectomy. Cancer Res. 2000;60(6):1585-94. doi.

40. Ali AS, Gronberg M, Federspiel B, Scoazec JY, Hjortland GO, Gronbaek H, et al. Expression of p53 protein in high-grade gastroenteropancreatic neuroendocrine carcinoma. PLoS One. 2017;12(11):e0187667. doi:10.1371/journal.pone.0187667.

41. Nielsen K, Binderup T, Langer SW, Kjaer A, Knigge P, Grondahl V, et al. P53, Somatostatin receptor 2a and Chromogranin A immunostaining as prognostic markers in high grade gastroenteropancreatic neuroendocrine neoplasms. BMC Cancer. 2020;20(1):27. doi:10.1186/s12885-019-6498-z.

42. Okubo Y, Yoshioka E, Suzuki M, Washimi K, Kawachi K, Kameda Y, et al. Diagnosis, Pathological Findings, and Clinical Management of Gangliocytic Paraganglioma: A Systematic Review. Front Oncol. 2018;8:291. doi:10.3389/fonc.2018.00291.

43. Okubo Y, Kasajima R, Suzuki M, Miyagi Y, Motohashi O, Shiozawa M, et al. Risk factors associated with the progression and metastases of hindgut neuroendocrine tumors: a retrospective study. BMC Cancer. 2017;17(1):769. doi:10.1186/s12885-017-3769-4.

44. Singh KB, Ji X, Singh SV. Therapeutic Potential of Leelamine, a Novel Inhibitor of Androgen Receptor and Castration-Resistant Prostate Cancer. Mol Cancer Ther. 2018;17(10):2079-90. doi:10.1158/1535-7163.MCT-18-0117.

45. Okubo Y, Nukada S, Shibata Y, Osaka K, Yoshioka E, Suzuki M, et al. Primary solitary fibrous tumour of the prostate: A case report and literature review. Malays J Pathol. 2020;42(3):449-53. doi.

46. Park JW, Lee JK, Witte ON, Huang J. FOXA2 is a sensitive and specific marker for small cell neuroendocrine carcinoma of the prostate. Mod Pathol. 2017;30(9):1262-72. doi:10.1038/modpathol.2017.44.

47. Xin Z, Zhang Y, Jiang Z, Zhao L, Fan L, Wang Y, et al. Insulinoma-associated protein 1 is a novel sensitive and specific marker for small cell carcinoma of the prostate. Hum Pathol. 2018;79:151-9. doi:10.1016/j.humpath.2018.05.014.

48. Kalos M, Askaa J, Hylander BL, Repasky EA, Cai F, Vedvick T, et al. Prostein expression is highly restricted to normal and malignant prostate tissues. Prostate. 2004;60(3):246-56. doi:10.1002/pros.20043.

49. Garudadri G, Rao BV, Sundaram C, Fonseca D, Murthy SS, Sharma R, et al. Diagnostic utility of immunohistochemical marker prostein for evaluation of primary and metastatic prostatic carcinomas. Indian J Pathol Microbiol. 2020;63(Supplement):18-24. doi:10.4103/IJPM.IJPM_852_18.

50. Seipel AH, Samaratunga H, Delahunt B, Wiklund P, Clements M, Egevad L. Immunohistochemistry of ductal adenocarcinoma of the prostate and adenocarcinomas of non-prostatic origin: a comparative study. APMIS. 2016;124(4):263-70. doi:10.1111/apm.12504.

\section{Tables}

Table 1. Clinicopathological data for each case 


\begin{tabular}{|c|c|c|c|c|c|c|c|c|}
\hline Case & $\begin{array}{l}\text { Age } \\
\text { (years) }\end{array}$ & Histological type & $\begin{array}{l}\text { Serum } \\
\text { NSE level } \\
(\mathrm{ng} / \mathrm{mL})\end{array}$ & $\begin{array}{l}\text { Serum } \\
\text { ProGRP } \\
\text { level } \\
(\mathrm{pg} / \mathrm{mL})\end{array}$ & $\begin{array}{l}\text { Serum } \\
\text { PSA level } \\
(\mathrm{ng} / \mathrm{mL})\end{array}$ & GG & Metastasis & $\begin{array}{l}\text { Outcome } \\
\text { (months) }\end{array}$ \\
\hline 1 & 89 & $\begin{array}{l}\text { Prostatic carcinoma with diffuse } \\
\text { NE differentiation }\end{array}$ & 16.1 & 84.6 & 51.5 & 5 & Bone, liver, lymph node & DOD 19 \\
\hline 2 & 65 & Mixed SCNC-adenocarcinoma & 7.1 & 32.1 & 11.1 & 5 & Lymph node & AWD 46 \\
\hline 3 & 80 & $\begin{array}{l}\text { Prostatic carcinoma with diffuse } \\
\text { NE differentiation }\end{array}$ & 10.2 & 52.8 & 435.8 & 5 & Lymph node & $\begin{array}{l}\text { DOC 13 } \\
\text { (gastric } \\
\text { cancer) }\end{array}$ \\
\hline 4 & 84 & Mixed SCNC-adenocarcinoma & $\begin{array}{l}\text { Not } \\
\text { measured }\end{array}$ & $\begin{array}{l}\text { Not } \\
\text { measured }\end{array}$ & 146.3 & 5 & none & AWD 37 \\
\hline 5 & 67 & SCNC (pure type) & 47.3 & 1440.0 & 0.5 & $\begin{array}{l}\text { Not } \\
\text { applicable }\end{array}$ & Bone, lung, lymph node & DOD 9 \\
\hline 6 & 78 & $\begin{array}{l}\text { Mixed SCNC-adenocarcinoma } \\
\text { (A case after hormonal therapy) }\end{array}$ & 15.2 & 44.6 & 0.0 & 5 & $\begin{array}{l}\text { Bone, brain, liver, lung, } \\
\text { lymph node, skin }\end{array}$ & DOD 19 \\
\hline 7 & 76 & SCNC (pure type) & 210.0 & 12700.0 & 0.6 & $\begin{array}{l}\text { Not } \\
\text { applicable }\end{array}$ & Liver, lung & DOD 9 \\
\hline 8 & 77 & Mixed SCNC-adenocarcinoma & 13.5 & 35.5 & 15.8 & 5 & None & AWD 15 \\
\hline 9 & 60 & $\begin{array}{l}\text { Prostatic carcinoma with diffuse } \\
\text { NE differentiation }\end{array}$ & $\begin{array}{l}\text { Not } \\
\text { measured }\end{array}$ & $\begin{array}{l}\text { Not } \\
\text { measured }\end{array}$ & 754.8 & 5 & Bone, lymph node & AWD 16 \\
\hline 10 & 77 & $\begin{array}{l}\text { Prostatic carcinoma with diffuse } \\
\text { NE differentiation }\end{array}$ & 6.0 & 14.2 & 5172.5 & 5 & Bone & AWD 15 \\
\hline 11 & 78 & Mixed SCNC-adenocarcinoma & 18.5 & 35.7 & 13.6 & 5 & None & AWD 9 \\
\hline
\end{tabular}

Abbreviations: NSE, neuron-specific enolase; NE, neuroendocrine; ProGRP, pro-gastrin-releasing peptide; PSA, prostate-specific antigen; GG, Gleason Grade; SCNC, small cell neuroendocrine carcinoma; DOD, died of disease; AWD, alive with disease; DOC, died of other causes.

The means \pm standard deviations of serum NSE, ProGRP, and PSA values in SCNC were $51.9 \pm 78.7 \mathrm{ng} / \mathrm{mL}, 2381.3 \pm 5086.2 \mathrm{pg} / \mathrm{mL}$, and $31.3 \pm 56.7 \mathrm{ng} / \mathrm{mL}$, respectively, whereas these values in prostate cancer with diffuse NE differentiation were $10.8 \pm 5.1 \mathrm{ng} / \mathrm{mL}, 50.5 \pm 35.3 \mathrm{pg} / \mathrm{mL}$, and $1603.7 \pm 2396.5 \mathrm{ng} / \mathrm{mL}$, respectively (PSA values in the one case with hormonal therapy and unmeasured values were excluded). No significant differences (Student's t-test) in serum NSE, ProGRP, and PSA levels were observed between small cell carcinoma and prostatic carcinoma with diffuse NE differentiation (excluding cases treated with hormonal therapy). All of the adenocarcinomas confirmed in this study were classified as Gleason Grade 5.

Table 2. H-score and Ki-67 labeling index of various immunohistochemical markers for each case 


\begin{tabular}{|c|c|c|c|c|c|c|c|c|}
\hline Cases & Histological type & $A R$ & $\begin{array}{l}\text { Chromogranin } \\
A\end{array}$ & $\begin{array}{l}\text { Ki-67 labeling } \\
\text { index }\end{array}$ & Prostein & $P S A$ & $p 53$ & Synaptophysin \\
\hline \multirow[t]{2}{*}{1} & \multirow{2}{*}{$\begin{array}{l}\text { Prostatic carcinoma with diffuse NE } \\
\text { differentiation }\end{array}$} & 270 & 4 & \multirow[t]{2}{*}{$40.9 \%$} & 300 & 10 & 30 & 150 \\
\hline & & $(3 \times 90)$ & $(2 \times 2)$ & & $(3 \times 100)$ & $(1 \times 10)$ & $(2 \times 15)$ & $(2 \times 75)$ \\
\hline \multirow[t]{2}{*}{2} & \multirow{2}{*}{$\begin{array}{l}\text { Adenocarcinoma area in mixed SCNC- } \\
\text { adenocarcinoma }\end{array}$} & 300 & 1 & \multirow[t]{2}{*}{$26.8 \%$} & 240 & 80 & 300 & 120 \\
\hline & & $(3 \times 100)$ & $(1 \times 1)$ & & $(3 \times 80)$ & $(2 \times 40)$ & $(3 \times 100)$ & $(2 \times 60)$ \\
\hline \multirow[t]{2}{*}{3} & \multirow{2}{*}{$\begin{array}{l}\text { Prostatic carcinoma with diffuse NE } \\
\text { differentiation }\end{array}$} & 300 & 2 & \multirow[t]{2}{*}{$28.1 \%$} & 30 & 40 & 180 & 160 \\
\hline & & $(3 \times 100)$ & $(2 \times 1)$ & & $(1 \times 30)$ & $(2 \times 20)$ & $(3 \times 60)$ & $(2 \times 80)$ \\
\hline \multirow[t]{2}{*}{4} & \multirow{2}{*}{$\begin{array}{l}\text { Adenocarcinoma area in mixed SCNC- } \\
\text { adenocarcinoma }\end{array}$} & 270 & 1 & \multirow[t]{2}{*}{$10.5 \%$} & 300 & 160 & 1 & 120 \\
\hline & & $(3 \times 90)$ & $(1 \times 1)$ & & $(3 \times 100)$ & $(2 \times 80)$ & $(1 \times 1)$ & $(2 \times 60)$ \\
\hline \multirow[t]{2}{*}{6} & \multirow{2}{*}{$\begin{array}{l}\text { Adenocarcinoma area in mixed SCNC- } \\
\text { adenocarcinoma }\end{array}$} & 160 & 180 & \multirow[t]{2}{*}{$0.2 \%$} & 40 & 180 & 3 & 40 \\
\hline & & $(2 \times 80)$ & $(3 \times 60)$ & & $(2 \times 20)$ & $(2 \times 90)$ & $(1 \times 3)$ & $(2 \times 20)$ \\
\hline \multirow[t]{2}{*}{8} & \multirow{2}{*}{$\begin{array}{l}\text { Adenocarcinoma area in mixed SCNC- } \\
\text { adenocarcinoma }\end{array}$} & 120 & 40 & \multirow[t]{2}{*}{$22.7 \%$} & 270 & 0 & 20 & 210 \\
\hline & & $(2 \times 60)$ & $(2 \times 20)$ & & $(3 \times 90)$ & $(0 \times 0)$ & $(2 \times 10)$ & $(3 \times 70)$ \\
\hline \multirow[t]{2}{*}{9} & \multirow{2}{*}{$\begin{array}{l}\text { Prostatic carcinoma with diffuse NE } \\
\text { differentiation }\end{array}$} & 285 & 1 & \multirow[t]{2}{*}{$25.1 \%$} & 240 & 160 & 10 & 140 \\
\hline & & $(3 \times 95)$ & $(1 \times 1)$ & & $(3 \times 80)$ & $(2 \times 80)$ & $(2 \times 5)$ & $(2 \times 70)$ \\
\hline \multirow[t]{2}{*}{10} & \multirow{2}{*}{$\begin{array}{l}\text { Prostatic carcinoma with diffuse NE } \\
\text { differentiation }\end{array}$} & 300 & 90 & \multirow[t]{2}{*}{$15.3 \%$} & 120 & 100 & 240 & 210 \\
\hline & & $(3 \times 100)$ & $(3 \times 30)$ & & $(2 \times 60)$ & $(2 \times 50)$ & $(3 \times 80)$ & $(3 \times 70)$ \\
\hline \multirow[t]{2}{*}{11} & \multirow{2}{*}{$\begin{array}{l}\text { Adenocarcinoma area in mixed SCNC- } \\
\text { adenocarcinoma }\end{array}$} & 300 & 1 & \multirow[t]{2}{*}{$32.9 \%$} & 270 & 80 & 0 & 160 \\
\hline & & $(3 \times 100)$ & $(1 \times 1)$ & & $(3 \times 90)$ & $(2 \times 40)$ & $(0 \times 0)$ & $(2 \times 80)$ \\
\hline \multirow[t]{2}{*}{2} & SCNC area in mixed SCNC-adenocarcinoma & 270 & 1 & $71.7 \%$ & 100 & 40 & 300 & 120 \\
\hline & & $(3 \times 90)$ & $(1 \times 1)$ & & $(2 \times 50)$ & $(2 \times 20)$ & $(3 \times 100)$ & $(2 \times 60)$ \\
\hline 4 & SCNC area in mixed SCNC-adenocarcinoma & 270 & 90 & $33 \%$ & 270 & 10 & 5 & 9 \\
\hline & & $(3 \times 90)$ & $(3 \times 30)$ & & $(3 \times 90)$ & $(1 \times 10)$ & $(1 \times 5)$ & $(3 \times 3)$ \\
\hline 5 & SCNC (pure type) & 60 & 180 & $79.7 \%$ & 0 & 0 & 210 & 270 \\
\hline & & $(2 \times 30)$ & $(3 \times 60)$ & & $(0 \times 0)$ & $(0 \times 0)$ & $(3 \times 70)$ & $(3 \times 90)$ \\
\hline 6 & SCNC area in mixed SCNC-adenocarcinoma & 10 & 240 & $76.5 \%$ & 0 & 5 & 50 & 100 \\
\hline & & $(1 \times 10)$ & $(3 \times 80)$ & & $(0 \times 0)$ & $(1 \times 5)$ & $(1 \times 50)$ & $(2 \times 50)$ \\
\hline 7 & SCNC (pure type) & 0 & 40 & $88.6 \%$ & 0 & 0 & 0 & 90 \\
\hline & & $(0 \times 0)$ & $(2 \times 20)$ & & $(0 \times 0)$ & $(0 \times 0)$ & $(0 \times 0)$ & $(1 \times 90)$ \\
\hline 8 & SCNC area in mixed SCNC-adenocarcinoma & 270 & 90 & $59.7 \#$ & 240 & 0 & 40 & 90 \\
\hline & & $(3 \times 90)$ & $(3 \times 30)$ & & $(3 \times 80)$ & $(0 \times 0)$ & $(2 \times 20)$ & $(1 \times 90)$ \\
\hline 11 & SCNC area in mixed SCNC-adenocarcinoma & 0 & 60 & $85.9 \%$ & 0 & 0 & 0 & 80 \\
\hline & & $(0 \times 0)$ & $(2 \times 30)$ & & $(0 \times 0)$ & $(0 \times 0)$ & $(0 \times 0)$ & $(1 \times 80)$ \\
\hline
\end{tabular}

Abbreviations: AR, androgen receptor; NE, neuroendocrine; PSA, prostate-specific antigen; SCNC, small cell neuroendocrine carcinoma

Staining intensity $(0-3)$ and staining percentage $(0-100)$ are provided in parentheses for the $\mathrm{H}$-scores. In practice, these values were multiplied to calculate the $\mathrm{H}$-score. Incidentally, Case 6 was a reference because hormonal therapy was performed during the biopsy.

Table 3. H-score and Ki-67 labeling index for each immunohistochemical marker 


\begin{tabular}{|c|c|c|c|}
\hline & $\begin{array}{l}\text { SCNC (H-score, } \\
\text { mean } \pm S D)\end{array}$ & $\begin{array}{l}\text { Adenocarcinoma area in mixed SCNC-adenocarcinoma } \\
(\mathrm{H} \text {-score, mean } \pm S D)\end{array}$ & $\begin{array}{l}\text { Prostatic carcinoma with diffuse NE differentiation } \\
(\mathrm{H} \text {-score, mean } \pm S D)\end{array}$ \\
\hline AR & $145 \pm 138.7$ & $247.5 \pm 86.2$ & $288.8 \pm 14.4$ \\
\hline $\begin{array}{l}\text { chromogranin } \\
\text { A }\end{array}$ & $76.8 \pm 60.6$ & $10.8 \pm 19.5$ & $24.3 \pm 43.9$ \\
\hline $\begin{array}{l}\text { Ki-67 labeling } \\
\text { index }\end{array}$ & $69.8 \pm 20.8$ & $23.2 \pm 9.5$ & $27.3 \pm 10.5$ \\
\hline prostein & $101.7 \pm 125.3$ & $270 \pm 24.5$ & $172.5 \pm 120.9$ \\
\hline PSA & $1.7 \pm 4.1$ & $80 \pm 65.3$ & $77.5 \pm 66.5$ \\
\hline p53 & $92.5 \pm 129.9$ & $80.3 \pm 146.8$ & $115 \pm 112.7$ \\
\hline Synaptophysin & $134.8 \pm 109$ & $152.5 \pm 42.7$ & $165 \pm 31.1$ \\
\hline
\end{tabular}

Abbreviations: AR, androgen receptor; NE, neuroendocrine; PSA, prostate-specific antigen; SCNC, small cell neuroendocrine carcinoma; SD, standard deviation

Immunohistochemical results for small cell neuroendocrine carcinoma (SCNC, n=6, comprising two cases of pure SCNC and four cases of mixed SCNCadenocarcinoma), adenocarcinoma areas in cases of mixed SCNC-adenocarcinoma $(n=4)$, and prostatic carcinoma with diffuse NE differentiation ( $n=4)$, excluding one case in which hormonal therapy was performed. In principle, $\mathrm{H}$-scores were employed in the assessments. Only the Ki-67 labeling index was based on the percentage of hotspots.

Table 4. Results of hotspot driver mutations 


\begin{tabular}{|c|c|c|c|c|c|c|c|c|c|}
\hline Case & Histological type & $E G F R$ & $E R B B 2$ & FLT3 & NOTCH1 & PIKЗCA & PTEN & SGK1* & $S M A D 4$ \\
\hline 3 & $\begin{array}{l}\text { Prostatic } \\
\text { carcinoma with } \\
\text { diffuse NE } \\
\text { differentiation }\end{array}$ & & & & & & & & \\
\hline 4 & $\begin{array}{l}\text { Adenocarcinoma } \\
\text { area in mixed } \\
\text { SCNC- } \\
\text { adenocarcinoma }\end{array}$ & & & & & & & & \\
\hline 4 & $\begin{array}{l}\text { SCNC area in } \\
\text { mixed SCNC- } \\
\text { adenocarcinoma }\end{array}$ & & p.Val859Asp & & & & & & \\
\hline 5 & $\begin{array}{l}\text { SCNC (pure } \\
\text { type) }\end{array}$ & p.Gly873Arg & & p.Ser684Pro & p.His1601Leu & & & & \\
\hline 7 & $\begin{array}{l}\text { SCNC (pure } \\
\text { type) }\end{array}$ & & & & & $\begin{array}{l}\text { p. } \\
\text { His1047Arg }\end{array}$ & & $\begin{array}{l}\text { p. } \\
\text { Thr321fs*25 }\end{array}$ & \\
\hline 8 & $\begin{array}{l}\text { Adenocarcinoma } \\
\text { area in mixed } \\
\text { SCNC- } \\
\text { adenocarcinoma }\end{array}$ & & & & & & & & \\
\hline 9 & $\begin{array}{l}\text { Prostatic } \\
\text { carcinoma with } \\
\text { diffuse NE } \\
\text { differentiation }\end{array}$ & & & & & & & & \\
\hline 10 & $\begin{array}{l}\text { Prostatic } \\
\text { carcinoma with } \\
\text { diffuse NE } \\
\text { differentiation }\end{array}$ & & & & & & & & p.Gly358Arg \\
\hline 11 & $\begin{array}{l}\text { Adenocarcinoma } \\
\text { area in mixed } \\
\text { SCNC- } \\
\text { adenocarcinoma }\end{array}$ & & & & & & p.GIn245ter & & \\
\hline 11 & $\begin{array}{l}\text { SCNC area in } \\
\text { mixed SCNC- } \\
\text { adenocarcinoma }\end{array}$ & & & & & & & & \\
\hline
\end{tabular}

Abbreviations: NE, neuroendocrine; SCNC, small cell neuroendocrine carcinoma

Results of hotspot driver mutations for each case. Case 7 data were based on a FoundationOne CDx assay report.

${ }^{*}$ Since SGK mutations are unavailable in the lon AmpliSeq Cancer Hotspot Panel v2, they were analyzed only in Case 7, in which the FoundationOne CDx assay was applied. SGK mutations were not analyzed in other cases.

\section{Figures}
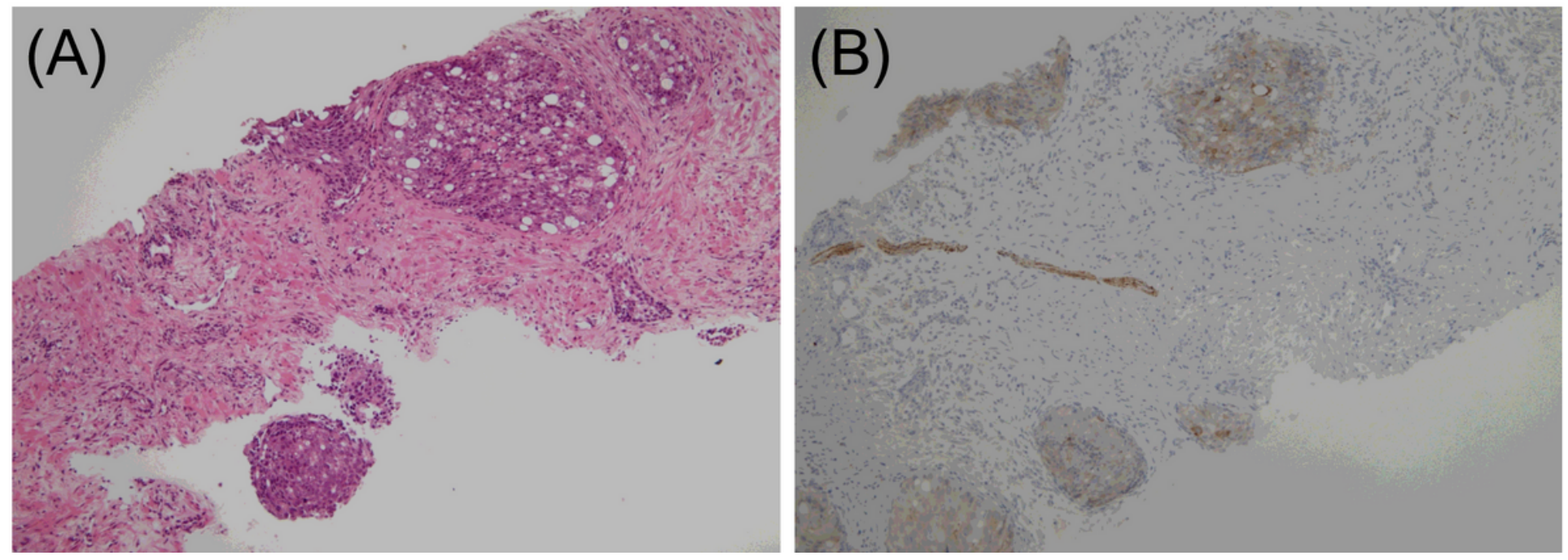
Figure 1

Histopathology of prostatic carcinoma with diffuse neuroendocrine differentiation. (A) Adenocarcinoma with cribriform structures. A low nuclear-tocytoplasmic ratio and foamy cytoplasm are observed (hematoxylin-eosin staining; original magnification, $\times 100$ ). (B) Immunostaining with synaptophysin. Moderate but diffusely stained carcinoma cells are noted (original magnification, $\times 100$ ).

100.0

80.0
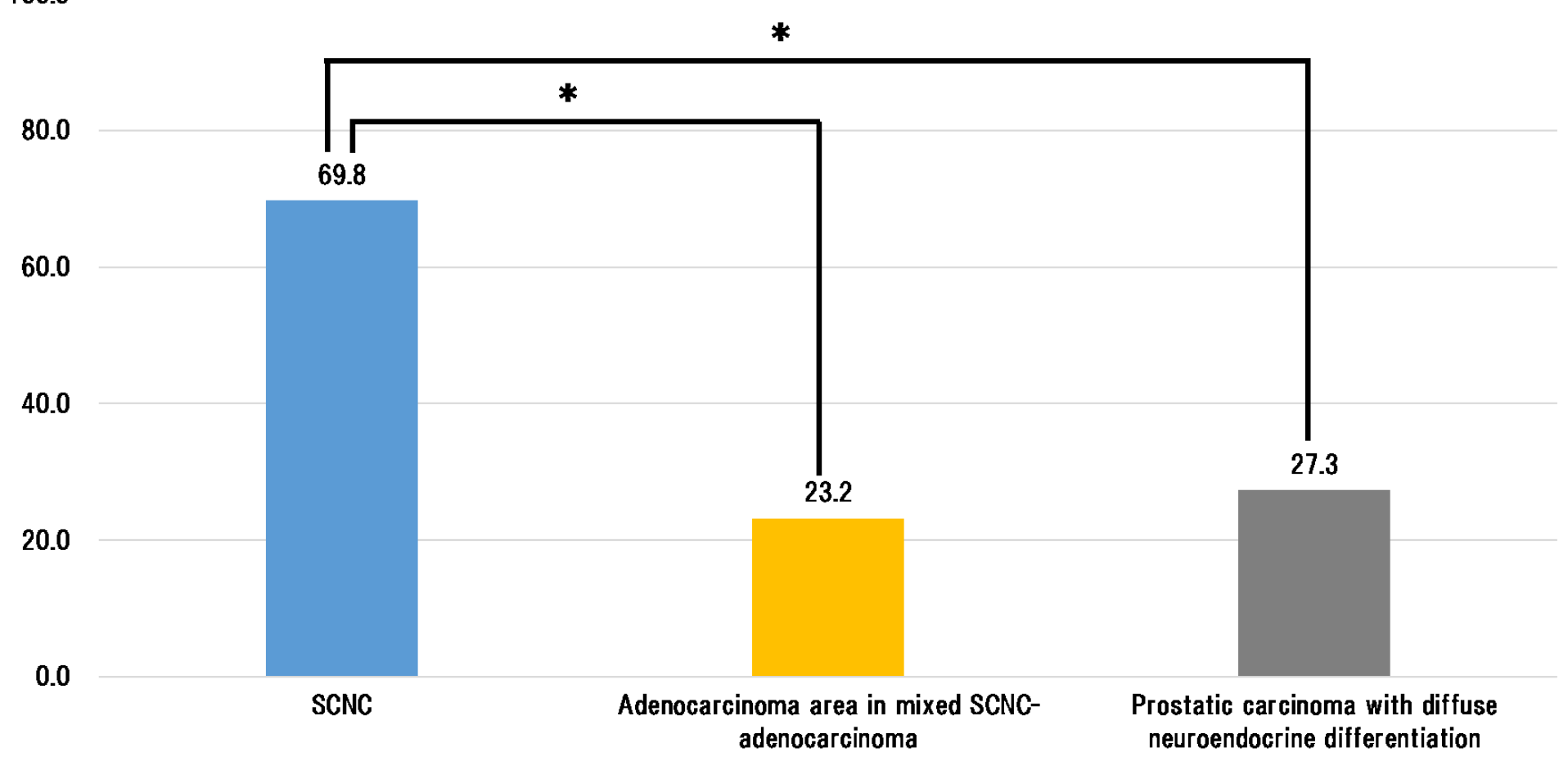

Figure 2

Ki-67 labeling index for each group. Ki-67 labeling index for the small cell neuroendocrine carcinoma (SCNC) group ( $n=6)$, adenocarcinoma area in mixed SCNC-adenocarcinoma group $(n=4)$, and prostatic carcinoma with diffuse neuroendocrine (NE) differentiation group ( $n=4)$ (excluding one case with hormonal therapy). The Ki-67 labeling index was higher in the SCNC group than in the other two groups (one-way analysis of variance and the Bonferroni post hoc test. P-values were $<0.01$, respectively).

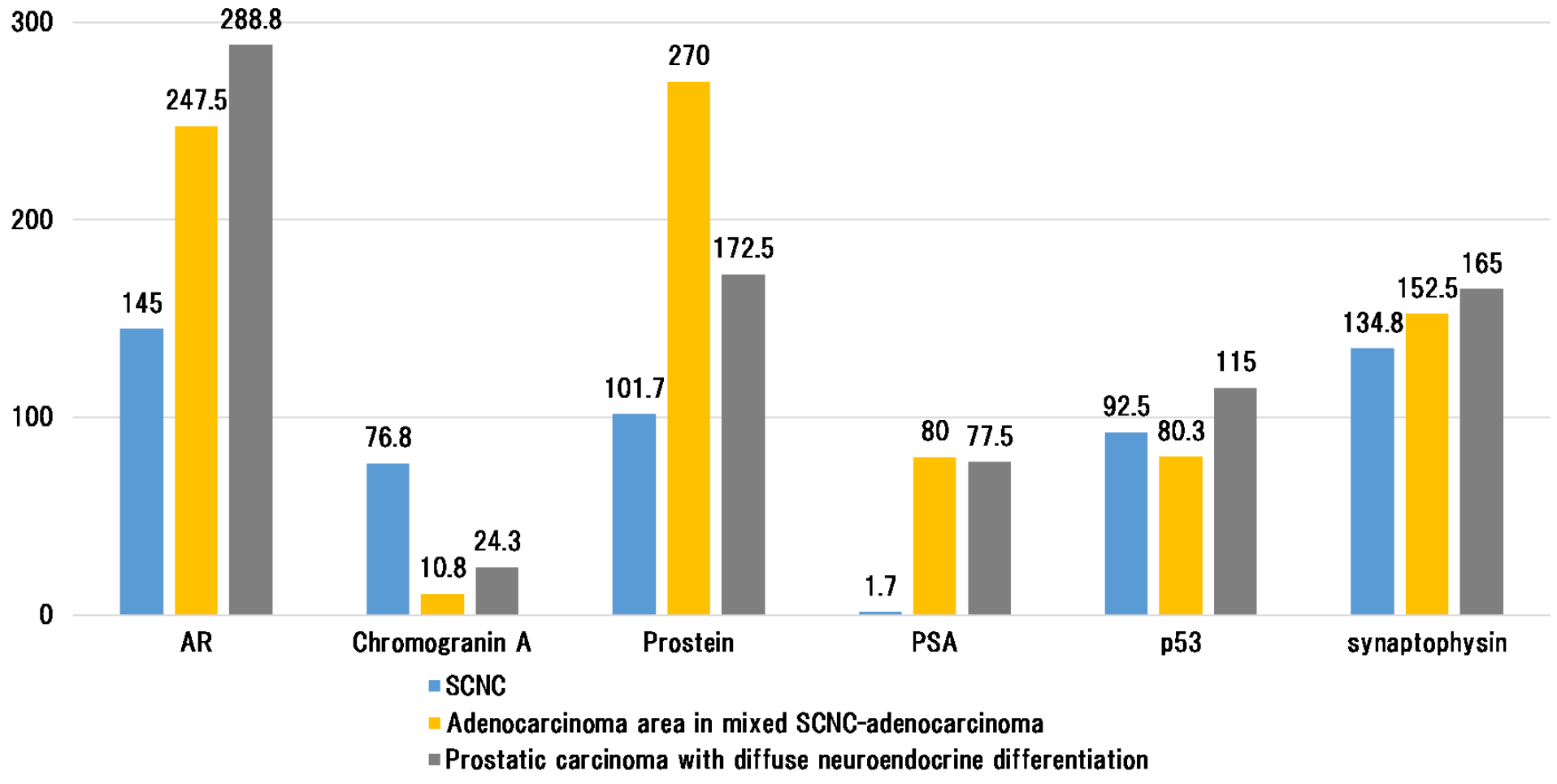

Figure 3 
$\mathrm{H}$-score for various immunohistochemical analyses. Immunohistochemical analyses (H-score) for small cell neuroendocrine carcinoma (SCNC, $\mathrm{n}=6$ ), adenocarcinoma area in mixed SCNC-adenocarcinoma $(n=4)$, and prostatic carcinoma with diffuse neuroendocrine (NE) differentiation ( $n=4)$ (excluding one case with hormonal therapy). No significant differences were observed between the three groups (one-way analysis of variance). Abbreviations: AR, androgen receptor; PSA, prostate-specific antigen.
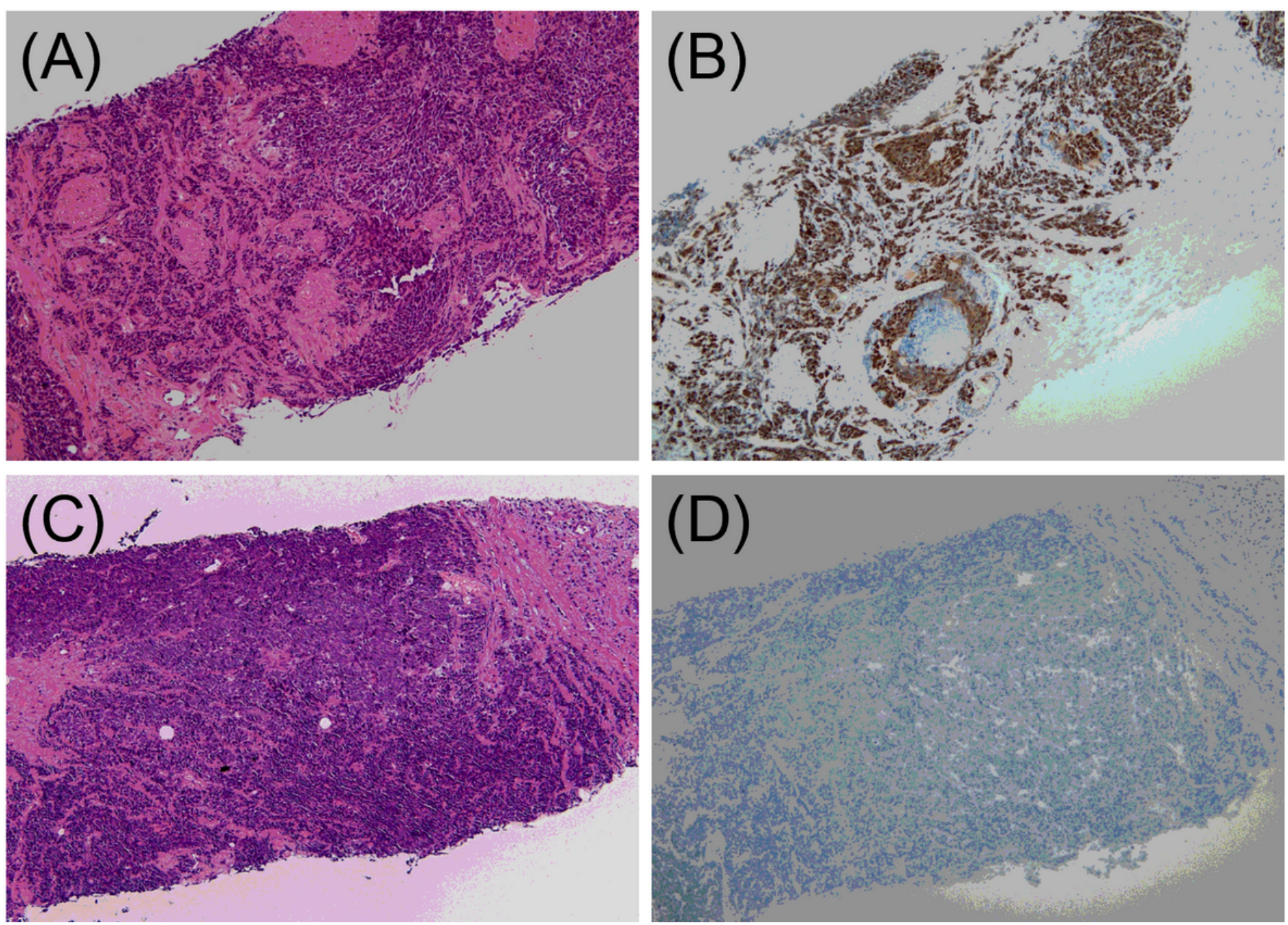

\section{Figure 4}

p53 expression in small cell neuroendocrine carcinoma. (A) Diffusely growing small cell neuroendocrine carcinoma (SCNC) with high nuclear-to-cytoplasmic ratio and small nuclei exhibiting dense chromatin staining (hematoxylin-eosin (HE) staining; original magnification, $\times 100$ ). (B) Carcinoma cells exhibiting p53 expression, with the exception of slight degeneration (original magnification, $\times 100$ ). (C) Confirmation of SCNC with diffuse proliferation (HE staining; original magnification, $\times 100$ ). (D) Carcinoma cells lacking immunoreactivity for $p 53$, referred to as null-type (original magnification, $\times 100$ ). 

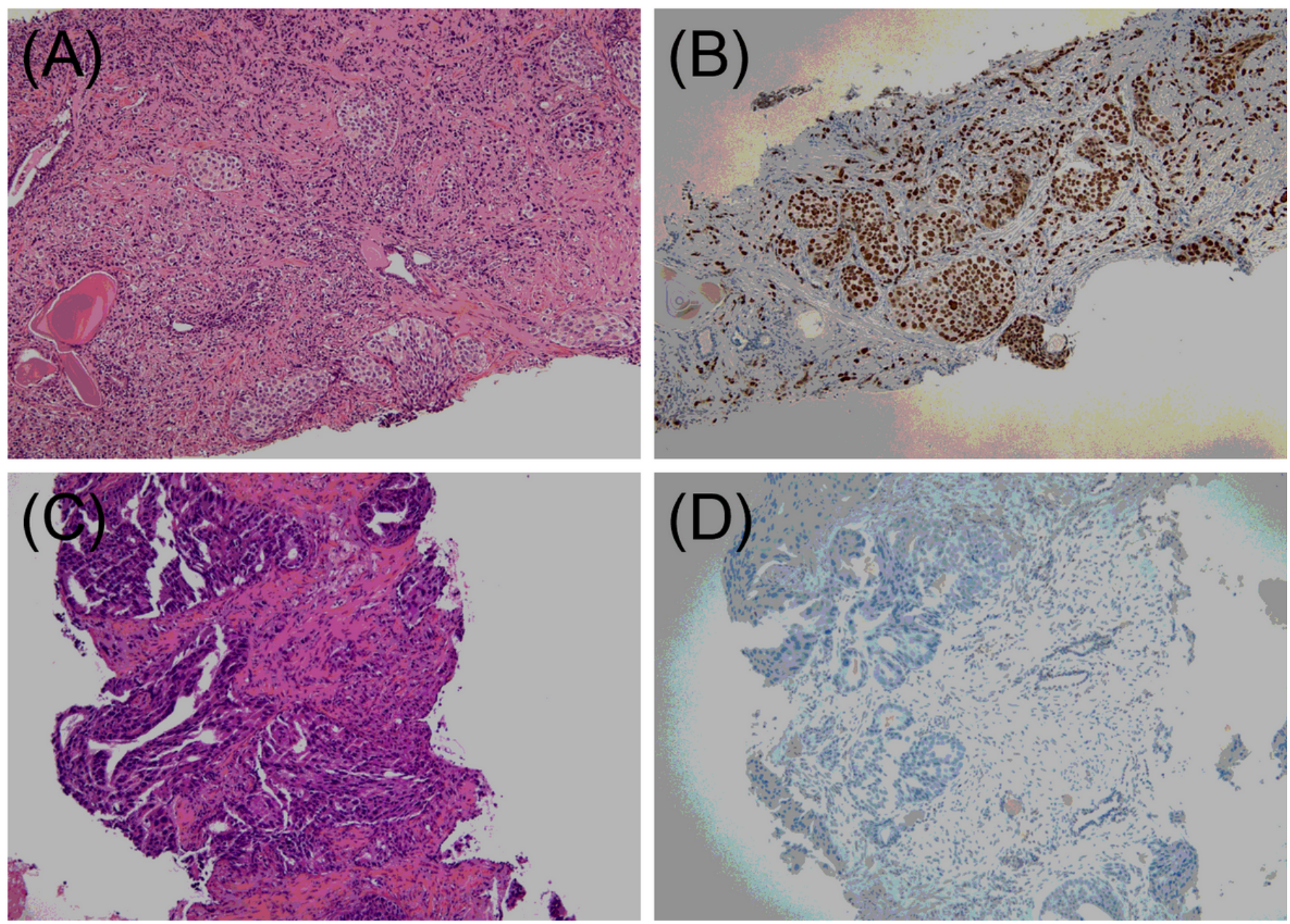

Figure 5

p53 expression in prostate cancer with diffuse neuroendocrine differentiation. (A) Adenocarcinoma exhibiting predominantly solid growth. The luminal structure is obscure, the nuclear-to-cytoplasmic ratio is low, and the cytoplasm is relatively pale and foamy (hematoxylin-eosin (HE) staining; original magnification, $\times 100$ ). (B) Carcinoma cells exhibiting p53 expression (original magnification, $\times 100$ ). (C) Adenocarcinoma with evidence of cribriform and luminal structures (HE staining; original magnification, $\times 100$ ). (D) Carcinoma cells lacking immunoreactivity for p53, referred to as null-type (original magnification, $\times 100)$. 